\title{
Hooking Up Data with Literacy: Creating an Educational Framework for Uppsala University Library
}

\author{
Nadja Duffner-Ylvestedt and Johanna Rayner* \\ Uppsala University Library
}

\begin{abstract}
Uppsala University Library offers a range of workshops and lectures for students and researchers in order to help them improve their information seeking skills, academic writing and critical scientific thinking. Our library education program mainly focuses on sources such as books or scholarly articles but students in many subject fields often face additional challenges since they have to handle large amounts of data. We identified the fact that we were hardly incorporating data management in our library education as a potential weakness. This project was developed in order to determine if the library should get involved in teaching data literacy.

The project involved gathering knowledge on how data is being taught at the university by conducting a student and teacher survey. A data module was developed and incorporated to the existing framework focusing on information literacy. The module was tested and evaluated by a pilot group of students. Our findings indicate that the University Library should begin teaching data literacy. We believe data to be one of the current challenges for Academic libraries and a key for staying relevant for students and researchers.
\end{abstract}

Keywords: academic libraries, library instruction, critical thinking, information literacy, data literacy, data information literacy, data management

\footnotetext{
*Contact:

Johanna Rayner

Uppsala University Library, Sweden

E-mail: johanna.rayner@ub.uu.se
} 


\section{Introduction}

Uppsala University Library offers a wide range of workshops and lectures to students and researchers in order to help them improve their information seeking skills, academic writing and critical scientific thinking. The library serves approximately 28000 students in eleven different subject libraries and the needs of faculty and students may vary depending on subject area. Libraries play an important part in teaching information literacy skill sets to students, often focusing on how to find, use and critically evaluate scholarly articles or books. As teaching librarians we realized that the students within the fields of Science, Technology and Medicine rely heavily on data to accomplish their assignments. They produce data themselves, access open data online and acquire data sets from teachers. If our goal is to teach information literacy to students, how do we provide the data skills needed? Is our educational framework lacking relevance if managing data is not part of the information literacy curriculum?

\section{Purpose of the project}

The overall purpose of the project was to investigate how students are taught data and data management at Uppsala University. We also wanted to find out if there is a need for the library to get involved in teaching data or if this is an area sufficiently covered by the faculty.

\section{Background}

There are several definitions of data literacy or data information literacy. One is put forth by Glenda A. Gunter who states that the student needs critical thinking skills in order to delve into data to figure out what it really means. The student also needs the ability to synthesize and evaluate data to create new information and knowledge after determining its quality (Gunter, 2007).

In order to become information literate, students have to develop many different skills. Thus, the library instruction's primary focus on books and articles might be insufficient. The current need for other focus points is partly connected to how science is evolving since e-science and open access is now making a lot of data available online. This is one of the reasons why students need to become data literate (Gunter, 2007).

Justin L. Otto identified the need to educate students on how to find, use and evaluate data during their studies. His pilot project found that data literacy is an important part of information literacy, especially in certain subject areas (Otto, 2012). He concluded that the best way of helping students to become information and data literate is to hold library instruction sessions that focus on the intertwined nature of these two concepts (Otto, 2012).

Many students are potential future researchers and therefore it is important to become data literate early in the academic career. Don MacMillan emphasizes the importance of wellplanned and organized data management in order to make data accessible to the scientific community (MacMillan, 2014). The number of researchers making their data accessible increases every year but still difficulties remain. One way of solving this is to educate students enabling them to become data literate researchers.

The field of library and information science evolves continuously. With data management becoming increasingly important for universities, the library could contribute expert knowledge in these areas to meet the needs of both faculty and students (Federer, 2014). 


\section{Method}

Phase one of the project consisted of reviewing the concept data literacy in the perspective of Library and Information Science. The Data information literacy project (DIL) by Purdue University was one inspiration (Qin \& D’Ignazio, 2010).

Phase two of the project involved incorporating elements of data literacy into the regular library education, enabling us to test this new way of teaching information literacy on a target group of students. We identified Earth Science students about to write their bachelor thesis as a suitable test group. Prior to the library instruction session we established learning outcomes for the students. The overall learning outcome was that the students should become data literate in the context of their subject area. Furthermore, the overall learning outcome was divided into four subcategories:

- Students should be able to explain what open data is and how open data influences science

- Students should be able to find relevant data for their field of study and understand how data is connected to the publication process

- Students should be able to apply critical thinking strategies to data as a source type

- Students should have an understanding of the challenges that arise due to reuse of data and the importance of metadata and citation

We decided to incorporate data literacy into other elements that we teach, for example source criticism, in order to exemplify how information literacy skills and data literacy skills are connected. At the end of the session the students answered a survey to assess if they had met the learning outcomes as well as questions on the subject of data literacy and how they had been taught data earlier.

The third phase was dedicated to the evaluation of the library instruction session as well as the survey conducted with the students. The findings of the survey together with our overall impressions of the session and the students' responses gave us ideas on how to improve the data module.

The fourth phase involved reaching out to the faculty in a survey that was sent to teachers in the fields of Science, Technology, Earth Science, Medicine and Pharmacy. The survey had questions on how data is taught at Uppsala University and if there is a perceived need for the library to get involved. This phase enabled us to meet the overall purpose of the project.

\section{Results and discussion}

\section{Assessment of the educational module}

As mentioned previously, the learning outcomes for the students participating in the pilot education session were assessed in a student survey. Almost all of the students were able to explain the concept of open data after attending our library instruction session. The students showed interest in learning how to cite data and regarded this as important for themselves and the research community in general. The survey, which was answered by 35 students, showed that the respondents found it difficult to analyze and evaluate visualized data. During the instruction session we focused just briefly on data visualization based on the assumption that the Earth Science students already were familiar with this aspect. The survey also revealed that the students' level of knowledge regarding different parts of data literacy varied heavily. All of the students were able to find relevant data even if the amount of data they found varied greatly depending on thesis subject. We found that almost all of the students met the desired learning outcomes. However, 68\% requested more education and pointed out that they felt insecure regarding data management (figure 1). Given the nature of the academic program for Earth 
Science students these findings were rather surprising. This particular group of students was chosen because they use data in their academic studies and the level of insecurity found in this group points towards the possibility that students could benefit from more education on data. To reach any conclusions on how other students at Uppsala University experience their data education further investigations need to be conducted.

\section{Have you prior to this been given education on how to interpret, visualize or collect data?}

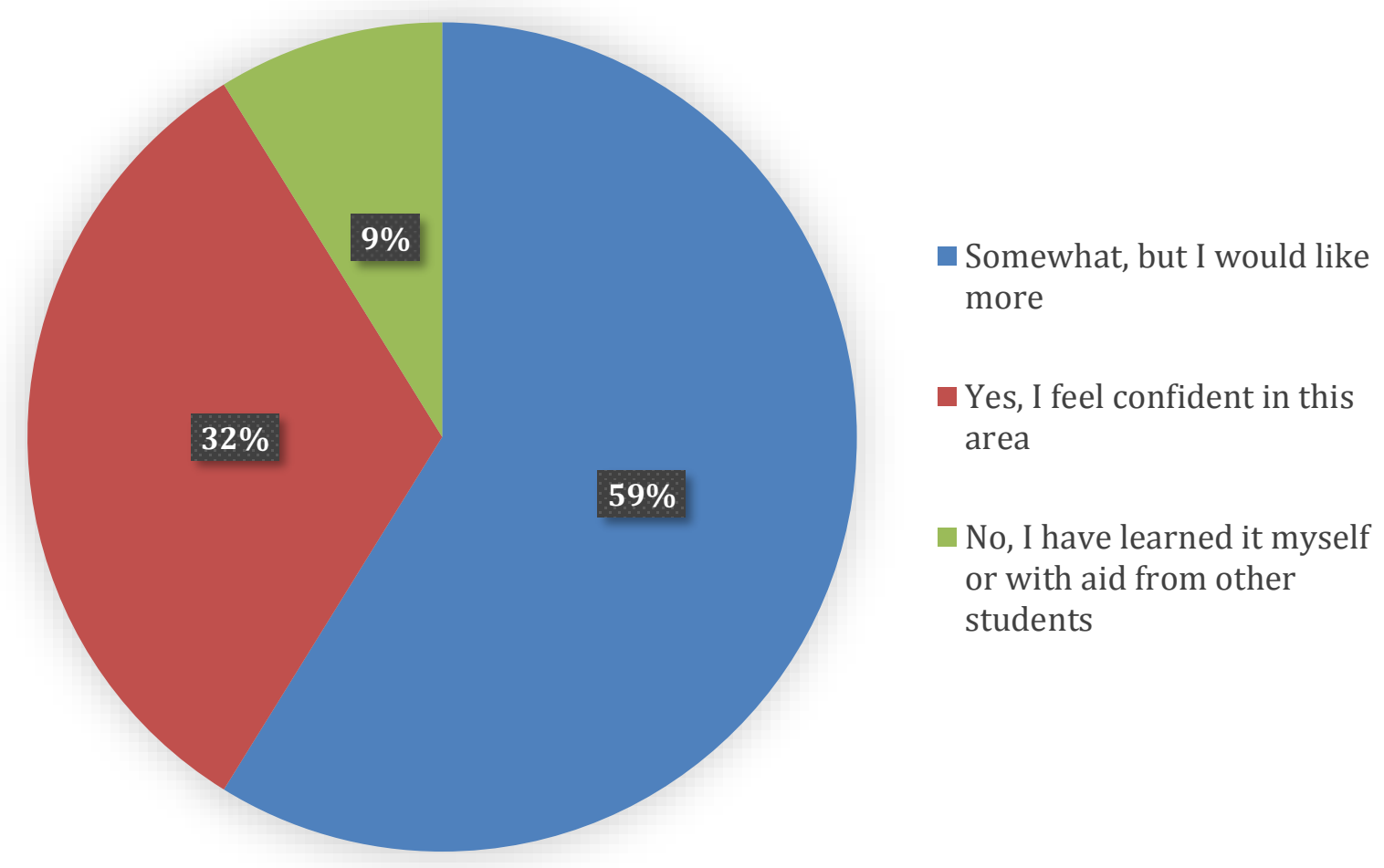

Figure 1. Results from the survey given to students $(n=35)$

Based on our research we see data literacy as an integral part of information literacy which is why we decided not to host a separate instruction session for the educational module on data literacy. The idea was to integrate that module into the regular three hour instruction session to highlight how interconnected data literacy and information literacy really are. We still think this is important, however, the assessment of the pilot library instruction showed that this is too much information to present in one class. The time required is also an issue to consider. Analyzing the results of the survey made us realize that not all the information was suited for the particular group of students. We therefore suggest that the educational module should be adjusted depending on the academic level of the students. The time issue could be solved by using other teaching methods, for example flipped classroom.

\section{Reaching out to faculty - the teacher survey analyzed}

The teachers answering the survey are employed at Uppsala University, in the fields of Medicine, Biology, Earth Science, Bioinformatics, Pharmacy, Data and Engineering Sciences. They teach students from undergraduate to $\mathrm{PhD}$ level. The results were collected during a two week period spring semester 2016, from 73 respondents. 
$94.5 \%$ of the teachers think it is important or essential that their students are able to locate and utilize data repositories and to evaluate the quality of the data available from external sources. It is also essential for teachers that the students have the ability to identify appropriate external data sources and know how to use them. Almost none of the teachers regard these areas of expertise as unimportant for their students.

$80.8 \%$ say that they use data sets from outside their lab as part of their research.

$94.6 \%$ regard it as important that the students are able to use basic visualization tools of the discipline to avoid misleading or ambiguous representations when presenting data in tables, charts or diagrams. The students should be able to choose the appropriate type of visualization such as maps, graphs, animations, or videos, based on their understanding of the purpose for visualizing or displaying data. When asked "Do you teach students how to interpret, visualize or collect data", $60.3 \%$ of the teachers would like more time to teach these areas. This corresponds with the students' opinion, where $68 \%$ requested more education (figure 1). This shows that it is very important for students to acquire these skills in order to be able to communicate with other researchers within their discipline. Communicating ideas and results via visualized data is an essential part of academic research.

We asked the teachers how important they believe it is for their students to understand the concept of metadata. We also asked how important it is for the students to be able to describe data so it can be understood and used, by themselves and others, as well as to develop the ability to read and interpret metadata from external disciplinary sources. Most teachers graded this as an important skill, yet only $9 \%$ responded that metadata is the most important concept to be taught by the University Library (figure 2).

We asked the respondents if they regard skills like understanding of intellectual property, privacy and confidentiality issues when it comes to sharing and administering data as important and if they incorporate these skills in their teaching and if so how. The trend that emerges is that the respondents think these are important areas to teach even if the responses vary.

The project's purpose was to determine if the library should get involved in teaching data literacy. To answer that question, we asked the respondents in which areas the University Library could become an asset in teaching data. Only $8 \%$ of the teachers did not consider this to be the University Library's responsibility (figure 2). The results show that ethical skills, finding data repositories, citing data and data visualization was the most requested areas (figure 2). All of the areas were regarded as important, something many respondents commented on in the additional comments field. The library should therefore aim for adding all of the components to the educational framework depending on academic level. 


\section{Which concept of data literacy is the most important to be taught by Uppsala University Library?}

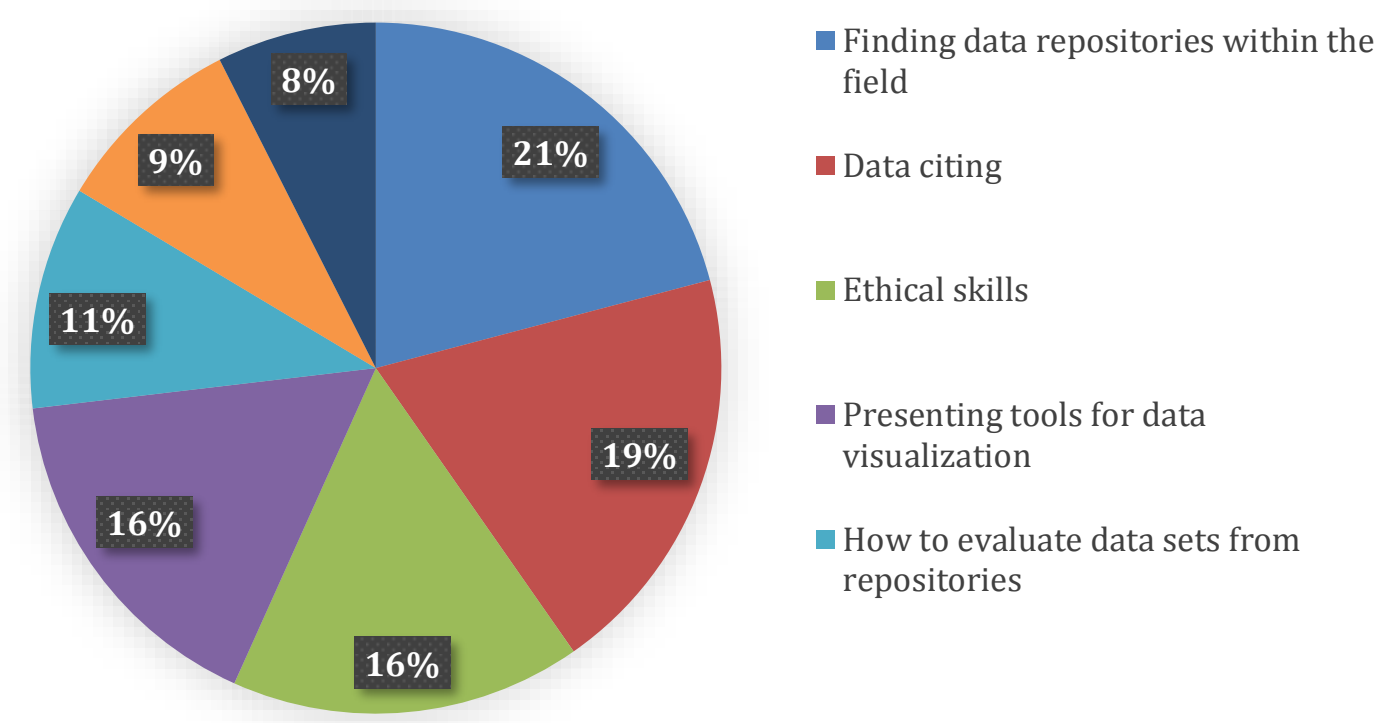

Figure 2. Results from the survey given to teachers $(\mathrm{n}=73)$.

\section{Conclusion}

The project of incorporating data literacy into Uppsala University Libraries' educational framework was concluded at the end of spring term 2016. We reached the following conclusions:

- Education in data literacy should differ depending on academic level and be adjusted so that it can be applied to different fields. We also believe that this type of library education will benefit from being planned together with teachers to combine different areas of expertise.

- Our literature review, combined with the answers from the student and teacher surveys, led us to the conclusion that Uppsala University Library should incorporate a data literacy module into its educational framework. We think this project revealed that the library could play an important role in ensuring that all students at Uppsala University get the same level of data literacy education.

- By recognizing that data literacy is connected and integrated to other concepts of literacy, students could be successfully supported to manage all areas of their studies. By doing so the Academic library will continue to stay relevant for students and faculty. 


\section{References}

Federer, L. (2014). Exploring new roles for librarians: The research informationist. Synthesis Lectures on Emerging Trends in Librarianship, 1(2), 1-47. http://doi.org/10.2200/S00571ED1V01Y201403ETL001

Gunter, G. A. (2007). Building student data literacy: An essential critical-thinking skill for the 21st century. MultiMedia \& Internet@Schools, 14(3), 24-28.

MacMillan, D. (2014). Data sharing and discovery: What librarians need to know. The Journal of Academic Librarianship, 40(5), 541-549.

http://doi.org/http://dx.doi.org/10.1016/j.acalib.2014.06.011

Otto, J. L. (2012). Assessing and improving data literacy: A study with urban and regional planning students. PNLA Quarterly, 76(4), 5-23. Retrieved from http://www.pnla.org/assets/documents/Quarterly/pnlaq76-4summer2012.pdf

Qin, J., \& D'Ignazio, J. (2010). Lessons learned from a two-year experience in science data literacy education. International Association of Scientific and Technological University Libraries, 31st Annual Conference. Retrieved from http://docs.lib.purdue.edu/iatul2010/conf/day2/5 